\title{
Ectopia renal cruzada y urolitiasis
}

\section{Crossed renal ectopia and urolithiasis}

\author{
Margarita María Sanz, Sonia Pilar Rodríguez • Bogotá, D.C.
}

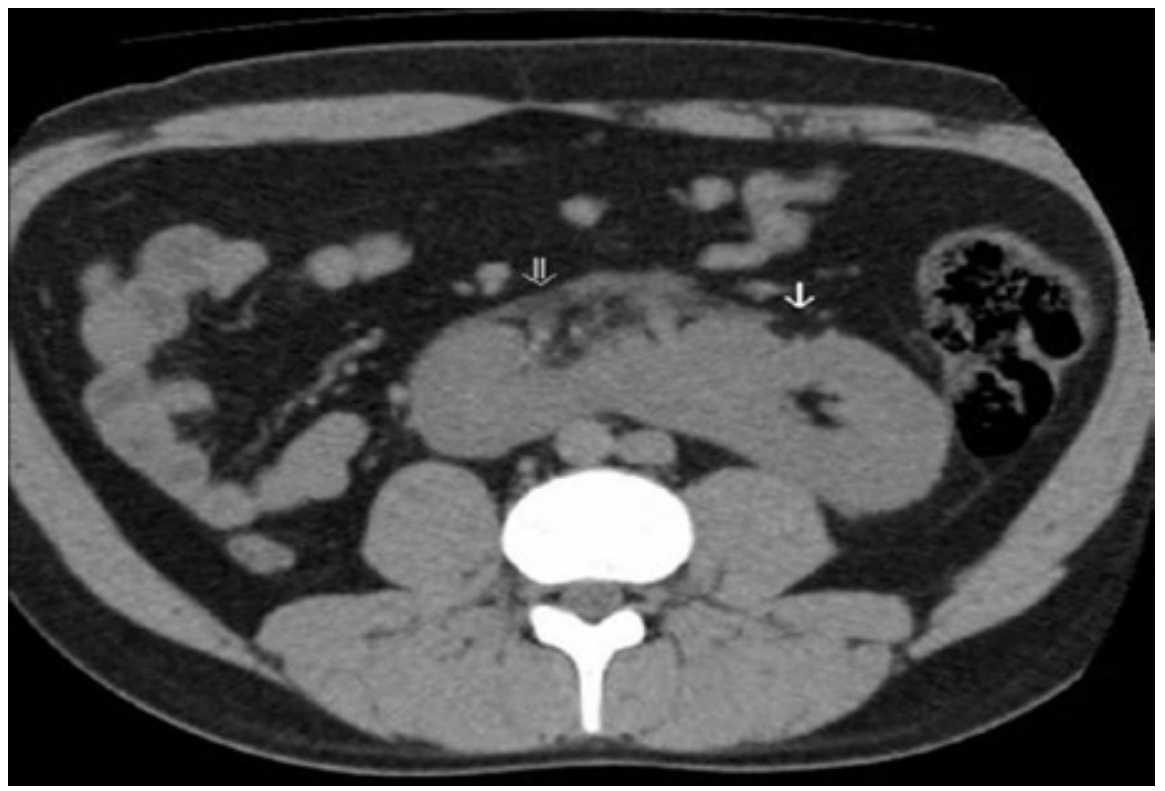

Panel A. Escanografía de abdomen simple corte axial: se observa el riñón izquierdo en la línea media (flecha blanca), con su polo superior fusionado al polo inferior del riñón derecho (flecha blanca doble).

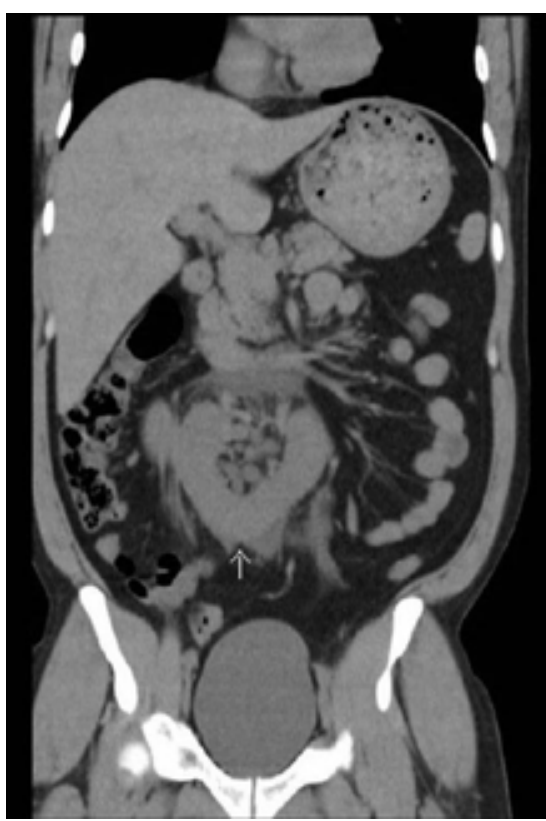

Panel B. Escanografía de abdomen simple corte coronal: el riñón izquierdo tiene una disposición horizontal, y se localiza en la línea media a nivel del mesogastrio (flecha blanca).

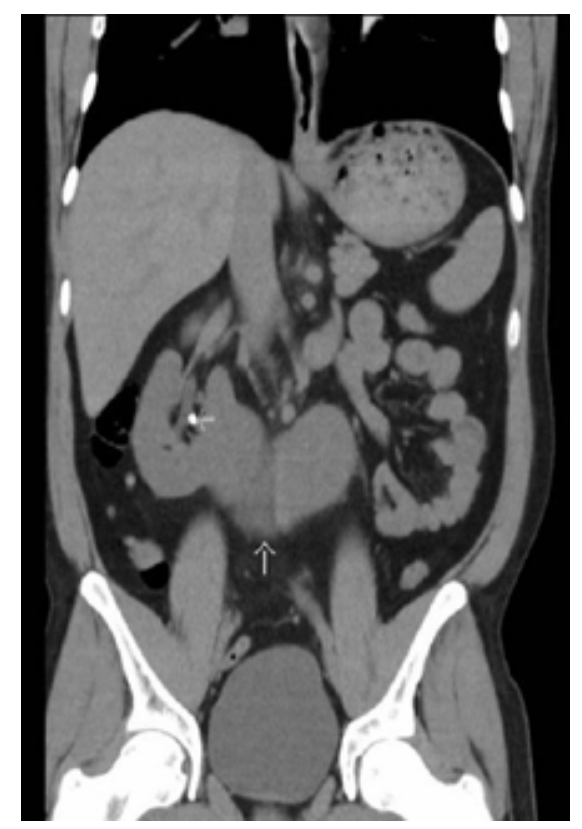

Panel C. Escanografía de abdomen simple corte coronal: el riñón izquierdo (flecha negra) se encuentra fusionado al polo inferior del riñón derecho. Se observa un cálculo de $7.2 \mathrm{~mm}$ en el grupo calicial inferior del riñón derecho (flecha blanca doble).
Paciente de 29 años de sexo masculino quien consultó por cuadro agudo de dolor lumbar izquierdo. Al examen físico se evidenció dolor a la palpación del hemiabdomen inferior, sin signos de irritación peritoneal. Con una impresión diagnóstica de cólico renoureteral se realizó una escanografía de abdomen simple donde se observó una ectopia renal cruzada. El riñón izquierdo se localizaba en la línea media, era de disposición horizontal, y su polo superior estaba fusionado al polo inferior del riñón derecho. Adicionalmente se identificó un cálculo en el grupo calicial inferior del riñón derecho.

La ectopia renal cruzada es una malformación renal congénita poco frecuente en la cual el riñón ectópico se localiza en el lado contralateral del abdomen, usualmente con fusión del polo superior del riñón ectópico con el polo inferior del riñón normal. Los cálculos afectan a estos riñones de la misma forma que a los riñones de localización normal.
Dra. Margarita María Sanz: Residente IV año de Radiología, Hospital Universitario San Ignacio, Pontificia Universidad Javeriana; Dra. Sonia Pilar Rodríguez: Residente IV año de Radiología, Hospital Universitario San Ignacio, Pontificia Universidad Javeriana. Bogotá D.C., Colombia.

Correspondencia: Dra. Margarita María Sanz E. Cra. 7 No. 40-62. Tel : 3208320. Ext 2357. Facultad de Medicina, Pontificia Universidad Javeriana, Bogotá, D.C., Colombia.

Email: msanz@javeriana.edu.co

Email: sopi_sopi@yahoo.com

Recibido: 15/IV/10 Aceptado: 12/VII/10 